\title{
Efficacy of Motivational Interviewing On Improving Resilience among Students with Below Average Academic Performance:
}

\section{A Case Study}

\author{
Riju Raj Roy ${ }^{1 *}$
}

\section{ABSTRACT}

There have been researches going on that have focused on strength based approach like resilience to motivate the students for improving their academic performances. Failing to perform well can create school difficulties like academic work related issues, adjustment to school environment, behaviour regulation, etc which may later stimulate mental health problems. Thus it is very important to early identify these issues to promote the best possible outcome for students. Though studies are very limited in counselling and education but it appears to suggest that Motivational Interviewing (MI) may be effective in addressing student's academic motivation to perform well. Thus the objective of the study was to assess the efficacy of Motivational Interviewing on improving resilience among students with below average academic performance. A student with below average academic performance was selected for the study from Dibrugarh Bengali High School, Dibrugarh, Assam. Pre and post assessment of the resilience level was assessed by using the Adolescent Resilience Scale. In between pre and post assessment, MI was applied to the student for 10 sessions alternatively. Post assessment and follow-ups were done to check any improvement on resilience. The result of the study concluded that at present Motivational Interviewing has shown to be effective on improving resilience among students with below average academic performance.

Keywords: Resilience, Motivational Interviewing, Academic Performance

Education is one of the key ingredients of human resource development. It is also referred as a fundamental human right as well as a catalyst for economic growth and human development (Okumu et al., 2008). Hence it positively nourishes one to deal effectively and make a significant contribution towards self and the society. It further psychologically strengthens an individual. Thus it is very important in life and every child should have and must get opportunity to achieve

\footnotetext{
${ }^{1}$ Clinical Psychologist, Hope Trust, Hyderabad, Telangana, India

*Responding Author

Received: January 16, 2017; Revision Received: February 19, 2017; Accepted: February 25, 2017

(C) 2017 Roy R; licensee IJIP. This is an Open Access Research distributed under the terms of the Creative Commons Attribution License (www.creativecommons.org/licenses/by/2.0), which permits unrestricted use, distribution, and reproduction in any Medium, provided the original work is properly cited.
} 


\section{Efficacy of Motivational Interviewing On Improving Resilience among Students with Below Average Academic Performance: A Case Study}

his or her academic potentials. Moreover education at secondary school level is supposed to be bedrock and the foundation towards higher knowledge in tertiary institutions. Studies conducted by Miller-Grandvaur and Yoder (2002) on secondary schools education found out that Secondary schools are an important part of the educational interventions. But, the main issues faced by secondary school education seem to be academic performance of students.

Most students in secondary school experience academic problem that manifests itself in the form of academic poor performance. It may cause difficulties like academic work related issues, adjustment to school environment, behaviour regulation, etc which may later stimulate mental health problems. Thus it is very important to early identify these issues to promote the best possible outcome for students. However, different people at different times have passed the blame of poor performance in secondary school to students because of their low retention, parental factors, association with wrong peers and low achievement motivation (Aremu \& Oluwole 2001).

The ongoing studies have sought to find out the factors leading to downward trend in the academic performance of secondary school students. Studies have shown that the level of family cohesion (Caplan et al, 2002 cited in Diaz, 2004), and family relationships (Buote, 2001) are capable of predicting academic performance. Even the interest of students in studies have been associated with volume of work completion, task orientation of the students and skill acquisition, personality and self-concept (Moore, 1973), feeling of inadequacy (Callaham, 1971), motivation and self-confidence (Aiken, 1976), anxiety (Aiken, 1970). Moreover, individual characteristics such as intelligence, cognitive styles, and personality play an important role in learning and instruction as does the context of learning. Among all the personal and psychological variables that have attracted researchers to study educational achievement, motivation seems to be more significant in relation to other variables (Tella, 2003). Moreover research has found the role of motivation to be central to educational resilience (Ruiz, 2002).

Researchers have also pointed resilience as a crucial component in boosting academics. Resilience has been conceptualized as an individual characteristic (Werner, 2000) and the term resiliency has been used to refer good, stable, and consistent adaption under challenging conditions (Masten, 1994). Academic resilience took more attention between different components. Academic resilience includes components such as confidence, a sense of wellbeing, motivation, an ability to set goals, relationships/connections, and stress management. It has been also linked with school and life outcomes including academic success for students who are faced with great adversity.

A handful of literature revealed strong evidence of resilience being connected to academic success. Scales et al. (2003) found that higher levels of resiliency traits were strongly correlated 


\section{Efficacy of Motivational Interviewing On Improving Resilience among Students with Below Average Academic Performance: A Case Study}

with higher grade point averages (GPAs) among middle and high school students. Similarly, Waxman and Huang (1997) reported that students with high rank on standardized tests were highly resilient, reported significantly higher levels of task orientation and satisfaction, social self-concept, achievement motivation, and academic self-concept than their counterparts who were low rankers.

Even studies have shown that resilient students sustain high levels of achievement motivation and performance despite the presence of stressful events and conditions that place them at risk of doing poor at school and dropping out of school (Alva, 1991). Thus learning skills of resilience or resilience development can benefit students to improve their performance in academics as these skills can have a lasting impact on academic performance.

Hence there have been studies going on that have focused on strength based approach like resilience to motivate the students for improving their academic performances. Though studies are very limited in counseling and education but it appears to suggest Motivational Interviewing (MI) as a client centre approach that may be effective in addressing student's academic motivation to perform well.

Motivational Interviewing, or MI, is goal oriented approach first introduced in the early 1980s by clinical professionals to help in the treating behavioural problems, such as alcoholism (Miller \& Rose, 2009; Miller, 2004). This technique has been found to be effective in facilitating behavioural changes in patients. Students who learn MI also can apply it to their own behaviours, resulting in better academic outcomes (Sheldon, 2010; Pintrich, 1990). Studies have reported that MI has produced significant positive changes in academic performance and self-reported positive academic behaviour (Bala \& Johansson, 2015).

Additionally, research on promoting academic achievement has found that the one single session of MI can have a beneficial effect on academic behaviours (Fuller \& Taylor, 2009).

However most of the studies done were an effort to show the relationship between MI and academic performances and have put more focus on different components like confidence level or self efficacy which influences resilience rather directly to studying resilience. Hence keeping this in concern this present study is an attempt to explore the efficacy of MI on improving resilience to influence academic performance.

\section{METHODOLOGY}

\section{Objective}

1. To explore the efficacy of Motivational Interviewing on improving resilience among students with below average academic performance. 


\section{Efficacy of Motivational Interviewing On Improving Resilience among Students with Below Average Academic Performance: A Case Study}

\section{Hypothesis}

1. There will be a significant difference in the level of resilience before and after Motivational Interviewing.

\section{Sample}

The sample consisted single participant with below average academic performance. The sample was drawn using purposive sampling. Participant had to be within the age range of 10-15 years. Additionally, participant afflicted by behavioural problems was excluded.

\section{Tools used}

1. Socio demographic data sheet

2. Adolescent Resilience Scale- ARS (Oshio, Kaneko, Nagamine and Nakaya, 2002)

The scale has 21 items in three subscales of novelty seeking, emotional regulation, and positive future orientation. Participants rated items using a score of 5 which means definitely yes and 1 which means definitely no. The Cronbach coefficients alpha was .75 for the Novelty Seeking, .73 for the Emotional Regulation, and .80 for the Positive Future Orientation. The overall consistency was .80, confirming the internal consistency of the whole scale.

Procedure

A participant with below average academic performance was selected for the study from Dibrugarh Bengali High School, Dibrugarh, Assam. Initially participant and his parents were informed about the study and the purpose of the study. Their consent was taken in the consent form. After that demographic information was collected and following that Pre assessment of the resilience level was assessed by using the Adolescent Resilience Scale. After that MI was conducted with the participant for 10 sessions alternatively. Later Post assessment and follow-up was done twice to check any improvement on resilience using the same scale.

Design:

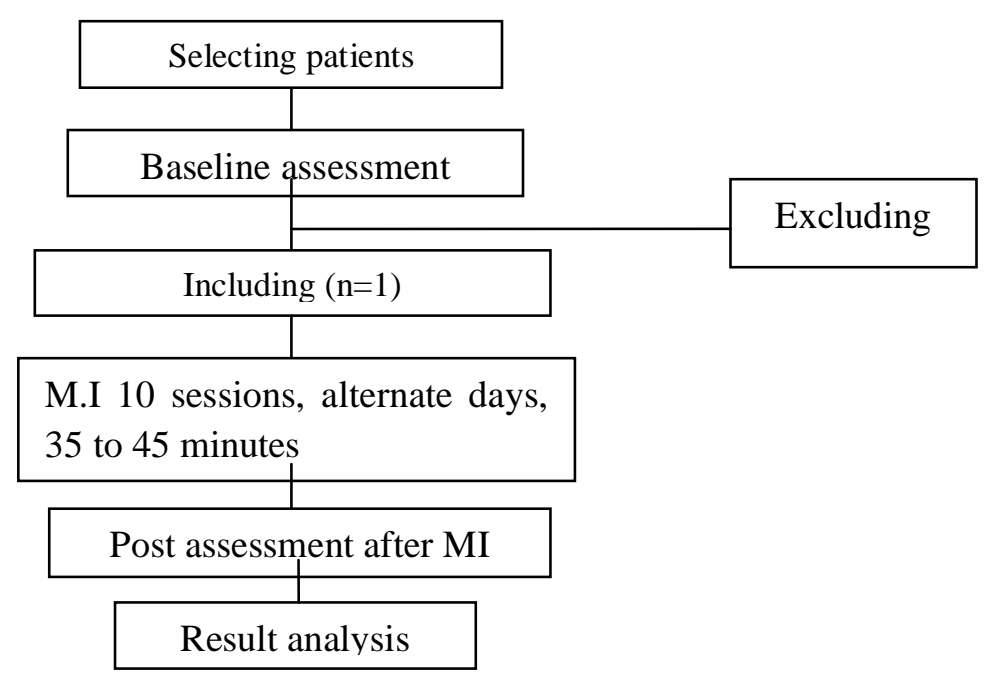

(c) The International Journal of Indian Psychology, ISSN 2348-5396 (e)| ISSN: 2349-3429 (p) | 129 


\section{Efficacy of Motivational Interviewing On Improving Resilience among Students with Below Average Academic Performance: A Case Study}

\section{Individual Session plan}

\begin{tabular}{|l|l|}
\hline Sessions & Activities/plans \\
\hline 1 & Formal interaction and rapport formation with the participant and family members. \\
\hline 2 & $\begin{array}{l}\text { Assessing participant and family member's awareness and concern about his } \\
\text { academic performance. }\end{array}$ \\
\hline 3 & Baseline assessment. \\
\hline 6 and 5 & $\begin{array}{l}\text { MI focused on cognitive dissonance regarding the problem based on participant's } \\
\text { perception about his academic performance and resilience. }\end{array}$ \\
\hline 8 and 9 & $\begin{array}{l}\text { MI focused on motivating resilience within the participant based on open ended } \\
\text { questions and reflection on self. }\end{array}$ \\
\hline 10 & $\begin{array}{l}\text { MI focused on dealing with the ambivalence regarding the academic performance } \\
\text { by summarizing the previous sessions. }\end{array}$ \\
\hline
\end{tabular}

\section{Case illustration}

Demographic details

Index participant was 14 years old, male, studying at $7^{\text {th }}$ grade from Dibrugarh, Assam. His father was a daily labor staying at a distant place and mother was a part time cook. He was the second child of his family. Based on his mother and school teacher's report and class test results, it was found that his academic performance was below average. He was not doing well in his exams since a long time. He was also warned of discontinuing his academics from the school by the principal if his performance does not get better. However no misconduct was reported. He was mentioned as regular, obedient in school keeping aside is academics. He was actively participating in sports. At home, he was reported as a responsible and caring son but with his studies he is not at all concerned. Whenever he was asked about his studies he would say that "ami kichu bhuji naa” and “ ami mone hoy pora shone korte parbo na”. The school teachers reported that from grade 1 to 7 , he has never cleared his all papers and was promoted each time under consideration. His mother took him to several astrologers and faith healers but no improvement was seen. A few months back he was referred for psychological evaluation by the school principle and was brought here. Currently he has completed 10 sessions of Motivational Interviewing and has attended his $2^{\text {nd }}$ follow up.

\section{Assessment}

As per the objective of the study, psychological assessment was done using:

\section{Adolescent Resilience Scale}

This test was used for both pre and post test assessment to check the level of resilience of the participant. On pre test, in this scale, the participant had a score of 57 indicating below average resilience level. On post test the score was 73 and 77 for $1^{\text {st }}$ and $2^{\text {nd }}$ follow-up respectively indicating above average level of resilience.

(c) The International Journal of Indian Psychology, ISSN 2348-5396 (e)| ISSN: 2349-3429 (p) | 130 


\section{Efficacy of Motivational Interviewing On Improving Resilience among Students with Below Average Academic Performance: A Case Study}

\section{Intervention}

Initial phase

This phase consisted three sessions in which the first session included formal interaction and rapport building with the participant and his parents. In the second session the parents were asked to report their awareness and concern towards participant's academic performance at present. In the third session the aim of the study was elaborately explained and confidentiality was assured to be maintained. The participant was briefly explained about MI and its procedure along with its benefits. Following that consent was taken and the Adolescent Resilience scale was administered.

\section{Middle phase}

The middle phase consisted of six sessions in which the first two sessions focused on cognitive dissonance regarding the problem based on participant's perception about his will to study and academic problem. In the second two sessions he was asked to summarize what he has understood from the last two sessions. Later he was asked few questions about how he exactly feels when he is not getting enough marks to pass his papers. The remaining two sessions focused on dealing with the ambivalence regarding the problem by summarizing the previous sessions. In these sessions whatever was explained to him was again discussed but the discussion was more from his point of view. In between he was rephrased anywhere he was having any doubt about anything he didn’t understand. The session was later disbanded congratulating him for his active participation for MI.

\section{Terminal phase}

This phase took place a week after completion of MI sessions. In this the participant was asked about his present condition and how he is dealing with his problem at present. He was also asked to briefly to rephrase what was discussed in the previous session. Later on similar follow ups were conducted twice along with administering the Adolescent Resilience Scale to assess his resilience level. The result was later discussed with him and his parents.

\section{RESULT}

On the basis of Motivational Interviewing, participant's report about his present condition and ARS post assessment scores which came to be 73 and 77 indicating above average resilience level, it can be suggested that Motivational Interviewing has been effective for this participant and at present he is resilient enough to make his academic performance better. There was a consistency of scores maintained by the participant in emotional regulation subscale (a score of 29 for both pre and post assessment). However there was a gradual increased score in novelty seeking and positive future orientation subscales in post assessment. For Novelty seeking subscale the participant had a score of 11 in pre assessment and 27 for both the post assessments. 


\section{Efficacy of Motivational Interviewing On Improving Resilience among Students with Below Average Academic Performance: A Case Study}

For positive future orientation, the participant had a score of 17 in pre assessment, 17 in $1^{\text {st }}$ post assessment and 21 in $2^{\text {nd }}$ post assessment.

\section{DISCUSSION}

The present study was carried out to assess the efficacy of Motivational Interviewing on improving resilience among students with below average academic performance. It was an attempt to explore if resilience score improves after MI was given which was assessed based on the scores obtain by the participant in the Adolescent Resilience Scale in the post assessment phase.

Following the assumption it was found that there was a gradual improvement in resilience score after Motivational Interviewing was given as mentioned in the result. It was also found that there was a gradual increase in scores for novelty seeking and positive future orientation subscales in pre and post assessment. However the participant had consistent score for emotional regulation subscale in both pre and post assessments.

Though there is a dearth of literature showing Motivational Interviewing as effective on improving resilience but there are studies that have shown MI to be effective on improving self efficacy which is a significant aspect of resilience. It was found that self-efficacy and selfconcept of students had a significant increase after Motivational Interviewing was given (Ashouri, Zolghadri, Nehmati, Alizadeh \& Ali Issazadegan, 2015). Another study reviewing 28 published articles have found that Motivational Interviewing is able to improve the development of skills and self-efficacy (Madson, Loignon, Lane, 2009). It can be further mentioned that Motivational Interviewing helps students to segregate their goals and strengthen its own values which can help in the process of changing their behavior and lead them to become successful students and contribute to the society (Butler, 2009). Further another study done by Stait etal. (2012) provided some preliminary support for the efficacy of MI for improving the academic performance of young adolescents. And it has been identified as a fundamental unit of change, perhaps one of the most efficient approaches to change (Embry \& Biglan, 2008).

\section{CONCLUSION AND IMPLICATION}

Thus based on the purpose and the result of the present study, it can be concluded that at present Motivational Interviewing has shown to be effective on improving resilience among students with below average academic performance.

In most of the literature Motivational Interviewing has been found to be effective in improving or modifying different aspect of self for better academic performance. Thus the present study can be useful in constructing an intervention package that will include Motivational Interviewing and its essential principles and features to solve the issue of lack of resilience among students with 
poor academic performance. Moreover it can also benefit the family members and teachers of the students in motivating them for reducing their stress and better dealing with their academics.

\section{Limitations}

1. The study is limited to only one participant. Thus the result cannot be taken for generalization.

2. The approach to the study was case study in nature. Thus there is a possibility of subjectivity.

3. The level of resilience was assessed by a single assessment tool.

4. Only two follow-ups were considered for post assessment of resilience level after intervention.

\section{Future direction}

1. The study may include a larger sample for better comparison.

2. The study may include multiple tools for assessing level of resilience.

3. The study may include multiple follow ups for better assessing the consistency in level of resilience.

\section{Acknowledgments}

The author appreciates all those who participated in the study and helped to facilitate the research process.

Conflict of Interests: The author declared no conflict of interests.

\section{REFERENCES}

Aiken, L. A. Jr. (1970). Attitudes towards Mathematics. Review of Educational Research, 40, 551-591.

Aiken, L. A. Jr. (1976). Update on attitudes and other affective variables in learning Mathematics. Review of Educational Research, 61, 880-815.

Alva, S. A. (1991). Academic invulnerability among Mexican- American students: The importance of protective resources and appraisals. Hispanic Journal of Behavioral Sciences, 13(1), 18-34.

Aremu, A. O., \& Oluwole, D. A. (2001).Gender and birth order as predictors of normal pupil's anxiety pattern in examination. Ibadan Journal of Educational Studies, 1(1), 1-7

Ashouri, M., Zolghadri, P., Nehmati, M., Alizadeh, S., \& Issazadegan, A. (2015). The Effectiveness of Motivational Interview on Enhancing Self-efficacy and Improving Selfconcept in Underdeveloped Students. American Journal of Educational Research, 3(7), 923-928. 


\section{Efficacy of Motivational Interviewing On Improving Resilience among Students with Below Average Academic Performance: A Case Study}

Bala, S., \& Johansson, V. (2012). The effect of motivational interviewing training on student's counseling skills and confidence: A systematic literature review. Master's Thesis in Odontology with Specialization in Oral Health, Malmo University.

Boute, C. A. (2001). Relation of autonomy and relatedness to school functioning and psychological adjustment. Dissertation abstract international section A: humanities and social sciences, 62(1).

Butler, S. H. (2009). Motivational interviewing: a school counselors guide. M.S dissertation, Winona State University.

Callaham, W. L. (1971). Adolescent Attitude towards Mathematics. Mathematics Teachers, 64, 751-753.

Caplan, S. (2012). Sociemotional factor contributing to adjustment among early entrance college students. Gifted Children Quarterly, 46(2),124-134.

Diaz, A. L. (2004). Personal, family, and academic factors affecting low achievement in secondary school. Electronic Journal of Research in Educational Psychology and Psychopedagogy, 1(1), 43 - 66.

Embry, D., \& Biglan, A. (2008). Evidence-based kernels: fundamental units of behavioral influence. Clinical Child and Family Psychology Review, 11(3), 75-113.

Fuller, C., \& Taylor, P. (2009). A Toolkit of Motivational Skills. West Sussex, England.

Madson, M. B., Loignon, A.C., \& Lane, C. (2009). Training in motivational interviewing: a systematic review. Journal of substance abuse treatment, 36, 101-109.

Masten, A. S. (1994). Resilience in individual development: Successful adaptation despite risk and adversity.

Miller, W. (2004). Motivational Interviewing: Facilitating Change across Boundaries. Mayo Clinic Proceedings, 79(3), 327-331.

Miller, W. R., \& Rose, G. (2009). Toward a Theory of Motivational Interviewing. The American Psychologist, 64(6), 527-537.

Miller-Grandvau, Y., \& Yoder, K. (2002). A literature review of community schools in Africa. Support for Analysis and Research in African (SARA) Project, Academy for Educational Development.

Moore, B. D. (1973). The Relationship of 5th grade students Self Concept and attitude towards mathematics to academic achievement in arithmetic computations, concept and application. Dissertation Abstract International, 32, 4426 A.

Okumu, I. M., Nakajjo, A., \& Isoke, D. (2008). Socio-Economic Determinants of Primary School Dropout: The Logistic Model Analysis.

Oshio, A., Kaneko, H., Nagamine, S., \& Nakaya, M. (2003). Construct validity of the adolescent resilience scale. Psychological Reports, 93(3f), 1217-1222.

Oshio, A., Nakaya, M., Kaneko, H., \& Nagamine, S. (2002). Development and validation of an adolescent resilience scale. Japanese Journal of Counselling Science, 35(1), 57-65. 


\section{Efficacy of Motivational Interviewing On Improving Resilience among Students with Below Average Academic Performance: A Case Study}

Pintrich, P. R., de Groot, E. V. (1990). Motivational and self-regulated learning components of classroom academic performance. Journal of Educational Psychology, 82(1), 33-40.

Ruiz, Y. (2002). Predictors of Academic Resiliency for Latino Middle School Students. Dissertation, Boston: Boston college.

Scales, P. C., Roehlkepartain, E. C., Neal, M., Kielsmeier, J. C., \& Benson, P. L. (2006). The role of developmental assets in predicting academic achievement: A longitudinal study. Journal of Adolescence, 29(5), 692-708

Sheldon, L. (2010). Using Motivational Interviewing to Help your Students. The NEA Higher Education Journal, 153-159

Strait, G. G., Smith, B. H., McQuillin, S., Terry, J., Swan, S., \& Malone, P. S. (2012). A Randomized Trial of Motivational Interviewing to Improve Middle School Students'academic Performance. Journal of Community Psychology, 40(8), 1032-1039.

Tella, A. (2003). Motivation and Academic Achievement in Mathematics.

Waxman, H. C., \& Huang, S. L. (1997). Classroom instruction and learning environment differences between effective and ineffective urban elementary schools for African American students. Urban Education, 32(1), 7-44.

Werner, E. E. (2000). Protective factors and individual resilience. Cambridge: Cambridge University Press, 115-132.

How to cite this article: Roy R (2017), Efficacy of Motivational Interviewing On Improving Resilience among Students with Below Average Academic Performance: A Case Study, International Journal of Indian Psychology, Volume 4, Issue 2, No. 92, ISSN:2348-5396 (e), ISSN:2349-3429 (p), DIP:18.01.114/20170402, ISBN:978-1-365-78192-6 